\title{
Quantification of blood flow in the portal circulation before and after an intervention
}

\author{
Alejandro Roldán-Alzate ${ }^{1 *}$, Alex Frydrychowicz ${ }^{1}$, Scott B Reeder ${ }^{1,2}$, Oliver Wieben ${ }^{1,2}$ \\ From 15th Annual SCMR Scientific Sessions \\ Orlando, FL, USA. 2-5 February 2012
}

\section{Summary}

PC-VIPR allows for characterization and quantification of hemodynamics in the entire hepatic system as well as inherent anatomical co-registration from a single scan. Results shown here reveal the potential of PC-VIPR for monitoring treatments for portal hypertension such as $\beta$-blockers and TIPS.

\section{Background}

Hemodynamic and morphological assessment of portal hypertension (PHTN) is challenging due to the dual blood supply to the liver and complex and variable anatomy. Additionally, in the presence of liver disease such as cirrhosis, the increased resistance to flow leads to changes in hepatic and splanchnic blood flow, which if measured, could have diagnostic value. Accurate noninvasive assessment of hemodynamics and morphology is challenging yet has potential to improve our understanding and diagnosis of PHTN. The purpose of this study was to evaluate a volumetric 4D flow-sensitive MR imaging method using radial undersampling (PCVIPR) for the analysis of portal circulation at baseline and after meal intervention.

\section{Methods}

Six volunteers without history of liver disease were included in this IRB-approved study. PC-VIPR ${ }^{1}$ was performed on a 3T MR scanner before and after a meal intervention with: $F O V=32 \times 32 \times 22 \mathrm{~cm}$, isotropic $1.3 \mathrm{~mm}$ spatial resolution, TR/TE $=6.1-7.8 / 2.1-3.2 \mathrm{~ms}$, Venc $=60 \mathrm{~cm} / \mathrm{s}$, scan time: $~ 10 \mathrm{~min}$ using respiratory and retrospective ECG gating. Vessel segmentation was performed in MIMICs using PC angiograms. Cut-planes were placed in EnSight and analyzed in MatLab ${ }^{2}$. Flow $(\mathrm{Q}[\mathrm{ml} / \mathrm{cycle}])$ in the superior mesenteric vein (SMV) and artery (SMA), splenic vein
(SV), porta vein (PV) and hepatic artery (HA) was quantified. The imaging exam was performed after at least 5 hours of fasting. A meal consisting of $591 \mathrm{~mL}$ EnSure plus $^{\circledR}$ (Abbott Laboratories, Columbus, OH; 700cal, 28\% from fat, $57 \%$ from carbohydrates) was provided to the subjects after a baseline scan. Scanning was resumed 20 min after the meal. For internal validation, mass conservation at the splenomesenteric confluence was performed $\left(\mathrm{Q}_{\mathrm{PV}}=\mathrm{Q}_{\mathrm{SMV}}+\mathrm{Q}_{\mathrm{SV}}\right)$.

\section{Results}

Segmentation quality of the hepatic and splanchnic angiograms was very good with excellent vessel detail in all cases. As shown in figure 2, large increases in flow were seen in the PV, SMV and SMA. Also, as expected, decreases in flow were seen in the SV and HA, although these decreases were not statistically significant. Finally, Internal validation $\left(\mathrm{Q}_{\mathrm{PV}}=\mathrm{Q}_{\mathrm{SMV}}+\mathrm{Q}_{\mathrm{sv}}\right)$ showed an acceptable error $(5.9 \pm 3.4 \%$ and $6.9 \pm 5.5 \%, \mathrm{p}=0.7)$ in the flow measurements at the confluence for baseline and intervention respectively.

\section{Conclusions}

PC-VIPR allows for characterization and quantification of hemodynamics in the entire hepatic system as well as inherent anatomical co-registration from a single scan. Figures 1 and 2 show the hemodynamic changes in portal circulation induced by the meal challenge and demonstrate that PC-VIPR successfully quantify changes in flow. Internal validation results demonstrate the validity of hepatic blood-flow measurements with PCVIPR. These results show the potential of PC-VIPR for monitoring treatments for portal hypertension such as $\beta$-blockers and TIPS. 


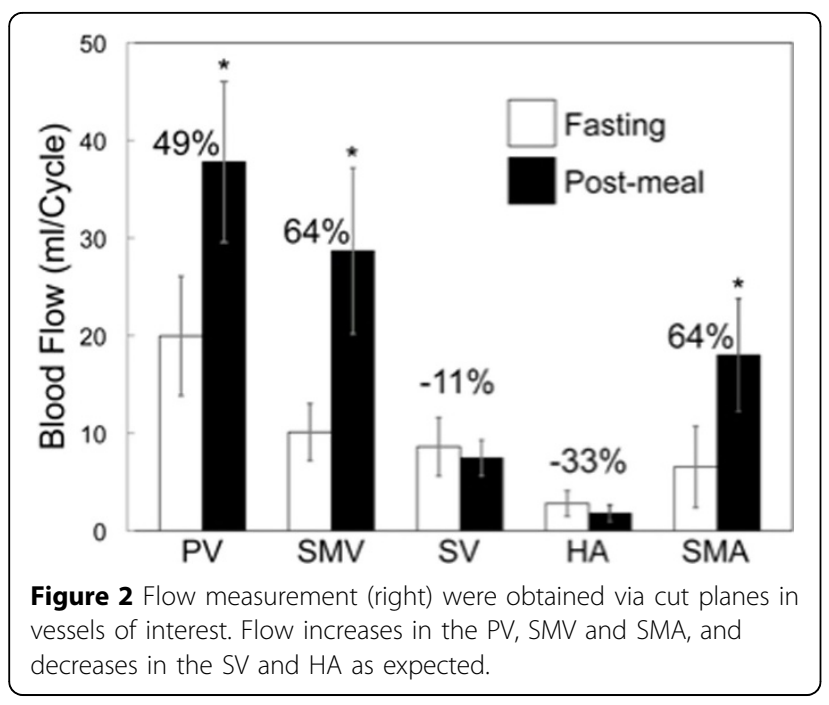

\section{Funding}

University of Wisconsin - Madison, Department of Radiology, Research and Development fund. R01 DK083380, R01 DK088925, RC1 EB010384.

\section{Author details}

${ }^{1}$ Radiology, University of Wisconsin, Madison, WI, USA. ${ }^{2}$ Medical Physics,

University of Wisconsin, Madison, Wl., USA.

Published: 1 February 2012

\section{References}

1. Johnson K: MRM. 2010

2. Stalder A: MRM. 2008.

doi:10.1186/1532-429X-14-S1-W11

Cite this article as: Roldán-Alzate et al:: Quantification of blood flow in the portal circulation before and after an intervention. Journal of

Cardiovascular Magnetic Resonance 2012 14(Suppl 1):W11.

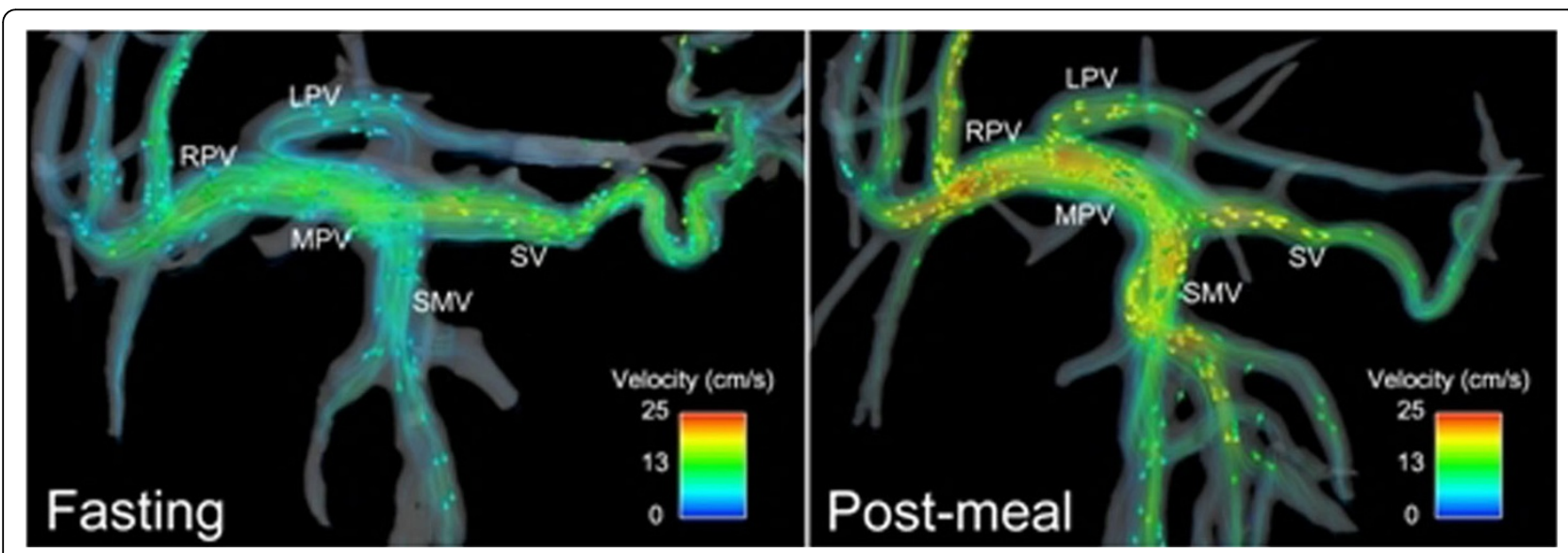

Figure 1 Changes in flow after a meal challenge in normal subjects $(N=6)$. Increased flow is easily visualized in the portal and splanchnic circulation before (left) and after (right) a meal.

Submit your next manuscript to BioMed Central and take full advantage of:

- Convenient online submission

- Thorough peer review

- No space constraints or color figure charges

- Immediate publication on acceptance

- Inclusion in PubMed, CAS, Scopus and Google Scholar

- Research which is freely available for redistribution 